\title{
Excised Twig Assay to Evaluate Cherry Rootstocks for Tolerance to Pseudomonas syringae pv. syringae
}

\author{
Elzbieta Z. Krzesinska' and Anita Nina Miller Azarenko \\ Department of Horticulture, Oregon State University, Cowallis, \\ OR 97331

\begin{abstract}
Additional index words. Prunus avium, P. cerasus, P. fruticosa, P. mahaleb,
\end{abstract} \\ $P$. pseudocerasus, bacterial canker
}

\begin{abstract}
Au excised twig assay was developed to evaluate cherry rootstocks (hybrids of Prunus avium L.; P. canescens Bois.; P. cerasus L.; P. fruticosa Pall.; P. mahaleb L.; P. pseudocerasus Lindl.) for their tolerance to Pseudomonas syingae pv. syringae van Hall. Twigs of 'Napoleon', 'Corum', and F12/1 in 1988 and 10 more rootstocks in 1989 were inoculated with water, one avirulent (K4), or one of three virulent strains (W4N54, AP1, and $\mathrm{B}-15)$ of bacteria at $10^{5}, 10^{6}$, and $10^{7}$ colony forming units (cfu)/ml in 1988 and with $10^{7} \mathrm{cfu} / \mathrm{ml}$ in 1989. Evaluation of browning and gummosis at the inoculation site after incubation for 4 weeks at $15 \mathrm{C}$ and high relative humidity revealed no gummosis or browning on twigs inoculated with water or the avirulent strain. The amount of browning and gummosis induced by concentrations of $10^{6}$ and $10^{7} \mathrm{cfu} / \mathrm{ml}$ of the virulent strains was, in general, not different within genotypes. 'Napoleon' and 'Corum' had significantly higher browning and gummosis ratings in 1989 than F12/1 and the 10 rootstock selections, most of which did not differ from F12/1. Rootstocks Gisela (Gi.) 172-9 and Gi. 169-15 had higher incision browning than F12/1 in some instances.
\end{abstract}

Bacterial canker, caused by Pseudomonas syringae pv. syingae is a serious disease of sweet cherries (Prunus avium L.) in the Pacific Northwest. Infection occurs primarily in the winter and early spring on aboveground portions of the tree. Typical symptoms include: trunk and shoot cankers, dead buds and blossoms, and, rarely, leaf and fruit lesions (Cameron, 1962a, 1962b). Infection

Received for publication 4 Mar. 1991. Accepted for publication 28 Aug. 1991. Oregon Agricultural Experiment Station Technical Paper no. 9781. This research was funded by the Oregon Regional Sweet Cherry Commission. Special thanks to Meadowlark Nursery Co. for providing the rootstock material and to Viki Freeman for her technical assistance. The cost of publishing this paper was defrayed in part by the payment of page charges. Under postal regulations, this paper therefore must be hereby marked advertisement solely to indicate this fact.

'Graduate Research Assistant.

${ }^{2}$ Assistant Professor may produce localized cankers and death of buds, limbs, or the entire tree.

Leaf-spot and killing of buds has been controlled successfully by spray applications, but control of the canker phase has generally been erratic (Cameron, 1962a). Chemical control and using copper compounds and streptomycin have led to the ap- pearance of resistant strains of bacteria (De Boer, 1980; Young, 1977).

Rootstock has been shown to influence the susceptibility of scion cultivars of plum (Prunus domestica L.) to bacterial canker (Shanmuganathan and Crosse, 1963). Cameron (1962b) showed that cherry trees grafted high $(\approx 100 \mathrm{~cm})$ on a tolerant rootstock sometimes have fewer cankers in the scion.

The primary cherry rootstocks used around the world are seedlings or clonal selections of Prunus avium known as 'mazzard' or F12/ 1 , respectively, and $P$. mahaleb, known as 'mahaleb' or 'St. Lucie'. F12/1 is reported to be tolerant to $P$. syringae pv. syringae in Oregon. Several interspecific hybrid rootstocks (Table 1) are currently being evaluated for horticultural acceptability in the United States. They include the "M $\times$ M" clones, which are hybrids of $P$. mahaleb $\mathrm{x}$ $P$. avium, and the Gisela clones (Gi.), which are interspecific hybrids among $P$. avium, $P$. canescens, $P$. cerasus, and $P$. fruticosa (Cummins, 1984). Little is known about the tolerance of these rootstocks to $P$. syringae pv. syringae.

Screening cherry rootstocks for resistance to bacterial canker is currently based on field observations over several years to minimize the influence of year-to-year variation in environmental conditions. The differences in environment, soil, and strains of the pathogen between locations may account for a cultivar being recorded as resistant in one area and susceptible in another. These limitations could be minimized by the development of a laboratory assay for resistance. Garrett (1981) inoculated potted cherry trees in a

Table 1. Parentage of cherry rootstocks evaluated in the excised twig assay (Cummins, 1984).

\begin{tabular}{|c|c|}
\hline Rootstock & Species or hybrid \\
\hline $\begin{array}{l}\text { F12/1 } \\
\text { Colt } \\
M \times M 2 \\
M \times M 39 \\
M \times M 60 \\
\text { Gi. } 148-1 \\
\text { Gi. } 148-8 \\
\text { Gi. } 154-2 \\
\text { Gi. } 154-5 \\
\text { Gi. } 169-15 \\
\text { Gi. } 172-9 \\
\text { Gi. } 173-9 \\
\end{array}$ & $\begin{array}{l}P . \text { avium } \\
P . \text { avium } \times P . \text { pseudocerasus } \\
P . \text { mahaleb } \times P \text {. avium } \\
P . \text { mahaleb } \times P . \text { avium } \\
P . \text { mahaleb } \times P \text {. avium } \\
P . \text { cerasus 'Schattenmorelle' } \times P \text {. canescens } \text { EMRS } \\
P . \text { cerasus 'Schattenmorelle' } \times P \text {. canescens } \text { EMRS } \\
P . \text { cerasus } \times P \text {. canescens } \\
P . \text { cerasus } \times P . \text { canescens } \\
P . \text { cerasus } \times P . \text { avium } \\
P . \text { fruticosa } 64 \times P \text {. avium } \\
P . \text { fruticosa } 64 \times P \text {. cerasus 'Schattenmorelle' }\end{array}$ \\
\hline
\end{tabular}



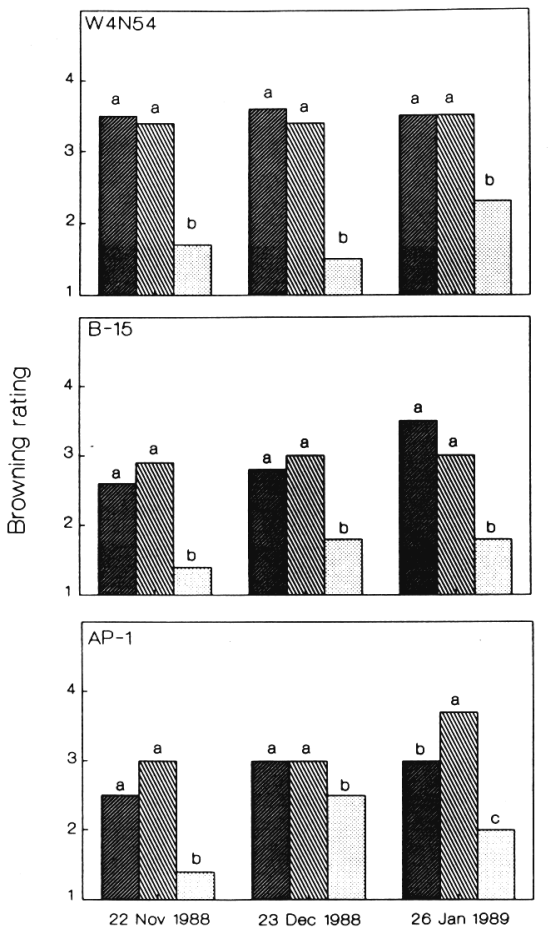

Fig. 1. Effect of inoculation with three virulent Pseudomonas syringae $\mathrm{pv}$. syringae strains $\left(10^{-7}\right.$ $\mathrm{cfu} / \mathrm{ml}$ ) on incision browning of 'Napoleon' (Y//), 'Corum' ( $\mathbb{N}$ (W), and F12/1 ( ) on three dates. Mean separation was by Waller-Duncan k-ratio $t$ test, k-ratio $=100$.

controlled-environment greenhouse, but it took 4 to 6 months before disease symptoms developed. An excised twig assay was used previously with peach to determine interaction between $P$. syringae and freezing (Weaver, 1978). The purposes of our study were to: 1) develop an excised-shoot assay for $P$. syringae pv. syringae tolerance that would be rapid and correlated with disease reaction in the field; 2) evaluate several rootstocks using the twig assay.

One-year-old twigs of 'Napoleon', 'Corum', and F12/1 were excised from trees growing at the Lewis-Brown Horticulture Research Farm, Oregon State Univ., Corvallis, on 22 Nov. and 23 Dec. 1988, and 26 Jan. 1989. Samples of the rootstock selections $(\mathrm{M} \times \mathrm{M}$ and $\mathrm{Gi}$. series) were collected at Meadowlake Nursery, McMinnville, Ore., on 20 Oct., 25 Nov., and 20 Dec. 1989. These dates were selected as they were coincident with the purported infection period in the field.

Twigs were placed in polyethylene bags and brought to the laboratory. Sections 20 $\mathrm{cm}$ long were excised from the apical end of each shoot. Twig sections were surface sterilized by dipping for 30 set in $75 \%$ ethanol, followed by $10 \mathrm{~min}$ in $0.05 \% \mathrm{v} / \mathrm{v}$ sodium hypochlorite. Twigs were then rinsed in distilled water three times and blotted dry. A 2-cm segment was cut from basal ends of twigs to remove portions that might have absorbed sodium hypochlorite. A sterile razor blade was used to make a longitudinal incision, $0.5 \times 2 \mathrm{~cm}$ flap on each twig to expose
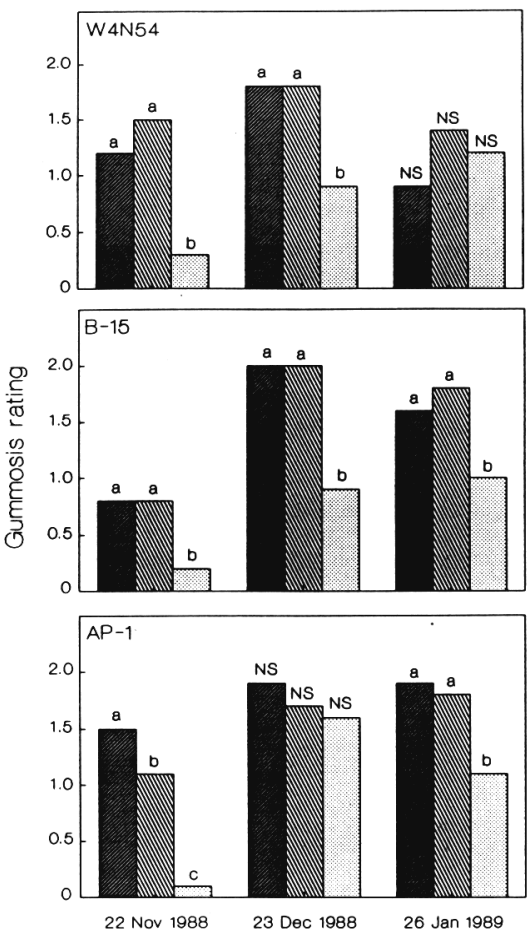

Fig. 2. Effect of inoculation with three virulent Pseudomonas syringae pv. syringae strains $\left(10^{-7}\right.$ $\mathrm{cfu} / \mathrm{ml})$ on incision gummosis of 'Napoleon' ( $/ / /)$, 'Corum' (W), and F12/1 ( ) on three dates. Mean separation was by Waller-Duncan k-ratio $t$ test, k-ratio $=100$.

the cambium. A $20-\mu l$ drop of bacterial suspension was placed in each incision with a sterile pipette. Three virulent (W4N54, AP1 , and B-15) and one avirulent (K-4) strain of $P$. syringae pv. syringae were used. Strains were cultured on King's medium B agar (King, 1954) for 3 days at 26C and bacteria suspended in sterile deionized water to a final cell concentration of $10^{5}, 10^{6}$, and $10^{7}$ colony forming units $(\mathrm{cfu}) / \mathrm{ml}$ the first year and $10^{7} \mathrm{cfu} / \mathrm{ml}$ the $2 \mathrm{nd}$ year). These concentrations were determined spectrophotometritally and confirmed by a standard dilution plate assay. Water inoculation was used as a control.

After inoculation, twigs were placed on water-saturated cotton wool in the bottom of sterile glass test tubes $(2.5 \times 25 \mathrm{~cm})$. Tubes were covered with plastic caps and incubated at $15 \mathrm{C}$ in darkness. Twigs were evaluated after 4 weeks for the amount of gummosis (0-2, $0=$ no gummosis) and browning of the incision $(1-4 ; 1=$ yellow pith, $4=$ dark brown).

A completely randomized design was used in both experiments. Ten twigs per genotype were used for each strain by concentration combination and sterile water inoculation. Data were analyzed using a general linear model procedure (SAS Institute, 1987). Differences among treatments were tested either by the Waller-Duncan k-ratio $t$ test or by using orthogonal contrasts.

Twigs inoculated with the avirulent strain or with water did not exhibit incision browning or induce gummosis, so mean ratings were 1.0 and 0.0 , respectively. Since inoculation with water and the avirulent strain did not cause browning or gummosis, the ratings were assumed to be an indicator of susceptibility.

In general, there was no concentration effect on incision browning or gummosis (data not shown). In a few instances, $10^{6}$ and $10^{7}$ cfu induced more browning and gummosis than $10^{5} \mathrm{cfu} / \mathrm{ml}$ with one exception, when $10^{5}$ and $10^{7} \mathrm{cfu}$ induced the highest browning response on 'Corum' inoculated with W4N54 on 23 Dec. 1988. Also, a higher gummosis rating was given to 'Napoleon' after inoculation with a bacterial suspension of W4N54 on 26 Jan. 1989 at $10^{5}$ and $10^{6}$ $\mathrm{cfu} / \mathrm{ml}$ than at $10^{7} \mathrm{cfu} / \mathrm{ml}$.

'Napoleon' and 'Corum' had the highest browning and gummosis ratings of the genotypes tested (Figs. 1, 2, and 3). Ratings for these two cultivars were similar and both appear to be highly susceptible to the pathogen in our excised twig assay, which agrees with results from field observations (H.R. Cameron, personal communication). F12/1 consistently had the lowest incision browning and gummosis ratings, suggesting that F12/ 1 is tolerant, rather than resistant, to $P$. syringae pv. syringae. This result, too, is consistent with field observations.

Rootstocks Gi. 172-9 and Gi. 169-15 were rated higher for browning than F12/1 on two of three dates when inoculated with strain W4N54 (Fig. 3). The other eight rootstocks were generally not different from F12/1. After inoculation with strain AP-1, only Gi. 1729, 'Napoleon', and 'Corum' had higher browning ratings than F12/1. A browning rating lower than F12/1 was observed on the last sampling date on rootstocks $\mathrm{M} \times \mathrm{M} 2$, Gi. 173-9, Gi. 148-8, and Gi. 154-2 after inoculation with all the virulent strains. Gummosis at the lesion of the inoculated rootstocks was only higher than that for F12/ 1 in one instance, i.e., on Gi. 169-15 twigs inoculated 20 Dec. 1989 with the AP-1 strain.

'Napoleon' and 'Corum', two cultivars that, based on field observations, are highly susceptible to the bacteria, had the highest browning and gummosis ratings in our assay. Lack of lesion browning and gummosis on twigs inoculated with water and an avirulent strain, compared with the results from inoculations with virulent strains, suggests that the excised twig assay provides a reliable assessment of resistance or tolerance. Only Gi. 169-15 and Gi. 172-9 appear to be more susceptible to $P$. syringae pv. syringae than F12/1 based on incision browning. The other eight rootstocks tested were as tolerant as $\mathrm{F} 12 / 1$.

Interestingly, the male parent of both $\mathrm{Gi}$. $169-15$ and Gi. $172-9$ is P. avium, a species generally highly susceptible to infection by $P$. syringae. $\mathrm{F} 12 / 1$ and the $\mathrm{M} \times \mathrm{M}$ series also have $P$. avium as the male parent. However, F12/1 was field selected for tolerance to $P$. syringae pv. morsprunorum (Webster, 1980). The selections of the $\mathrm{M} \times \mathrm{M}$ series in Oregon were based partly on field tolerance to $P$. syringae pv. syringae. The susceptibility of Gi. 169-15 and Gi. 172-9 may 

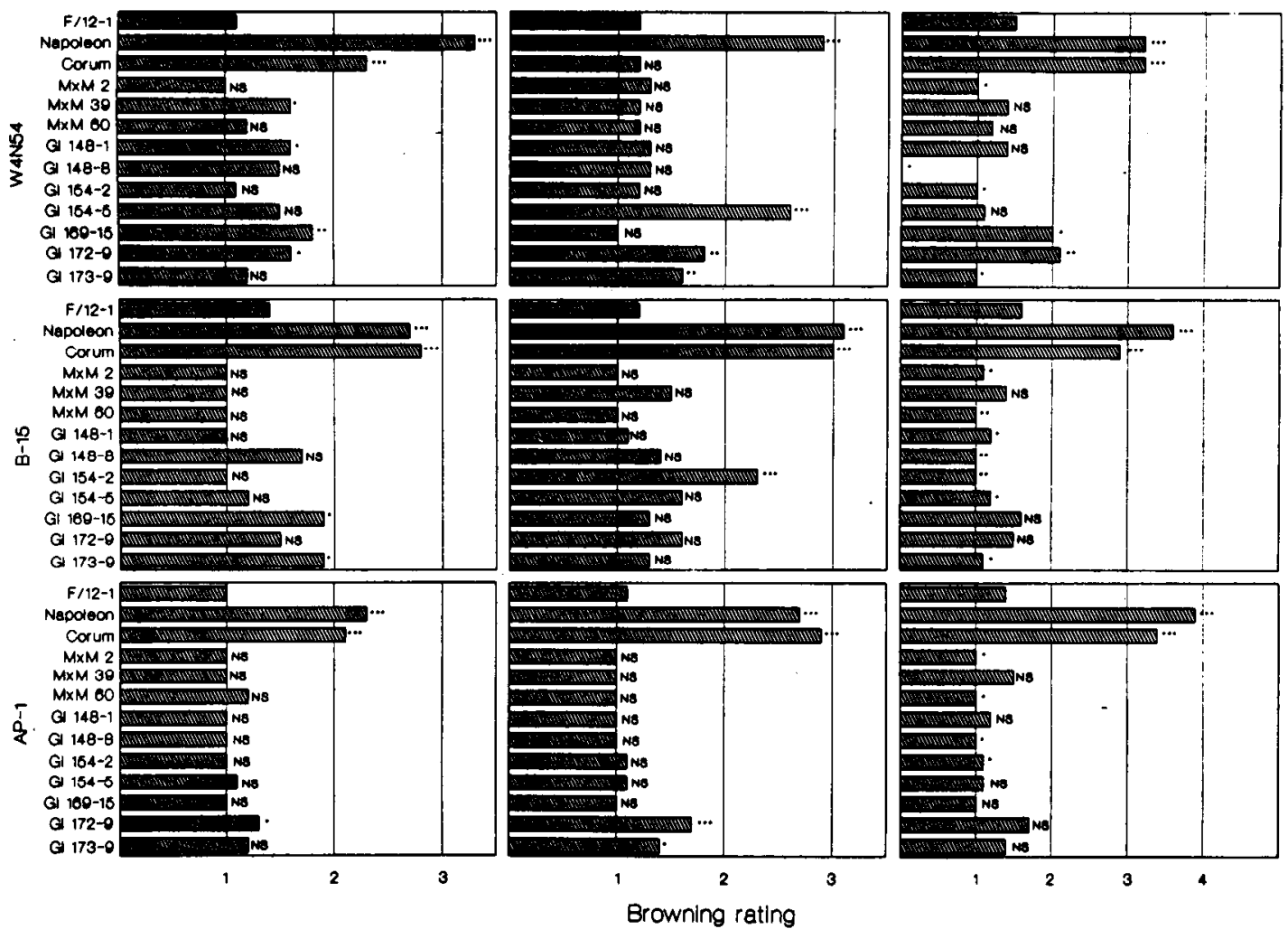

Fig. 3. Comparison of incision browning by orthogonal contrasts of F12/1 to 'Napoleon', 'Corum', and various cherry rootstocks after innoculation with three virulent strains of Pseudomonas syringae pv. syringae on three dates. $\mathrm{NS}$, $* * * * * *$ Nonsignificant of significant at $\mathrm{P}=0.05$, 0.01 , or 0.001 , respectively.

be a function of their $P$. avium parentage, as these were not initially screened for field tolerance to $P$. syringae pv. syringae as the $\mathrm{F} 12 / 1$ clone and the $\mathrm{M} \times \mathrm{M}$ series were.

The twig assay could be used to evaluate cherry genotypes on their susceptibility to $P$. syringae pv. syringae infection of shoots and trunk. Since most of the rootstocks had a similar response to inoculation as F12/1, susceptible scion cultivars could be grafted high onto these rootstocks to reduce the disease incidence on the scion and trunk canker on the rootstock. Additionally, these rootstocks might impart a level of size control or other desirable attribute on the vigorous scion cultivars.

\section{Literature Cited}

Cameron, H.R. 1962a. Mode of infection of sweet cherry by Pseudomonas syringae. Phytopathology 52:917-921.

Cameron, H.R. 1962b. Diseases of deciduous fruit trees incited by Pseudomonas syringae van Hall. Oregon Agr. Expt. Sta. Tech. Bul. 66.

Cummins, J.N. 1984. Fruit tree rootstocks recently introduced and soon to be introduced. Compact Fruit Tree 17:57-63.

De Boer, S.H. 1980. Leaf spot of cherry laurel caused by Pseudomonas syringae. Can. J. Plant Pathol. 2:235-238.

Garrett, C.M.E. 1981. Screening for resistance in Prunus to bacterial canker. Proc. 5th lntl. Conf. Plant Pathogenic Bacteria. p. 525-530.

King, E.O., M.K. Ward, and D.E. Raney. 1954.
Two simple media for demonstration of pyocyanin and fluorescin. J. Lab. Clin. Med. 44:301-307.

SAS Institute. 1987. SAS/STAT guide for personal computers, version 6 ed. SAS Institute, Inc., Gary, N.C.

Shanmuganathan, N. and J.E. Crosse. 1963. Experiments to test the resistance of plum rootstocks to bacterial canker. Annu. Rpt. East Malling Res. Sta. 1962:101-104.

Weaver, D.J. 1978. Interaction of $P$. syringae and freezing in bacterial canker on excised peach twigs. Phytopathology 68:1460-1463.

Webster, T. 1980. Dwarfing rootstocks for plums and cherries. Acta Hort. 114:201-207.

Young, J.M. 1977. Resistance to streptomycin in Pseudomonas syringae from apricot. N.Z. J. Agr. Res. 20:249-251. 